值为 2.000), 且信号强度随反应时间规 律 性 地 变 化. 这表明在 $\left(\mathrm{C}_{2} \mathrm{ZrH}_{2}\right)_{\mathrm{x}}$ 与 RNCS 反应的过程中 $\mathrm{Zr}-\mathrm{H}$ 键发生均裂, 反应经过自由基机理进行. 这 种在锆氢化物与不饱和化合物的反应中, $\mathrm{Zr}-\mathrm{H}$ 键
发生均裂的有趣现象文献中还未见报道.

王 梅 贝浼智 郭和夫 (中国科学院大连化学物理研究所)

\title{
沁水煤田北缘晚石炭世火山诱积碳酸盐岩的 发现及成因初探
}

在沁水煤田北缘阳泉荫营一带，发现一种特殊 类型的碳酸盐岩,它产于太原组四节石灰岩 $\left(K_{2}\right)$ 和 钱石灰岩 $\left(\mathrm{K}_{3}\right)$ 之间,厚 $1-3 \mathrm{~m}$ ，呈透镜状或似层状 夹于 13" 煤层底板砂岩中,貌似细砂岩. 经详细研 究, 应为“火山诱积碳酸盐岩”。在剖面上与凝灰岩 或层凝灰岩共生.

显微镜下,该岩石主由 $0.2-0.5 \mathrm{~mm}$ 的微晶方 解石“凝块”组成，含量大于 $80 \%$ ，“凝块”之间为亮 晶方解石充填，含量小于 $20 \%$ 。“凝块”常呈不规则 同心圆状或皮壳状，其核心多为火山碎屑物质所占 据. 经详细鉴定,这些火山碎屑物质主由玻屑、晶屑 和岩屑组成,占全部岩石的 $25-35 \%$ ．玻首常脱玻 化; 晶屑主为斜长石, 聚片双晶清楚; 岩屑主为安山 岩和安山玢岩岩屑; 晶屑和岩屑中斜长石为 An2530 中性斜长石, 其有序度为 $0.3-0.5$, 属高温斜长 石.

该岩石中不溶残渣的化学全分析结果相当于流 纹岩质和安山岩质凝灰岩, 用各种岩石化学方法㤆 复原岩的数据均落于岩浆岩区.

该岩石中粘土矿物主为水云母及少量蒙 脱 石, 表明 “火山诱积碳酸盐岩”形成于中性至弱碱性 环 境.

该岩石中氧、碳同位素比值为:

$$
\begin{aligned}
& \delta \mathrm{C}_{\mathrm{PDB}}^{13}=-1.19-+0.15 \%, \\
& \delta \mathrm{O}_{\mathrm{PDB}}^{18}=-13.13-14.09 \%,
\end{aligned}
$$

与海相石灰岩 $\left(K_{2}, K_{3}\right)$ 的比值相似，表明“火山诱 积碳酸盐岩”形成于咸水或半咸水环境.
该岩石中微量元素比值, 为 $\mathrm{B} / \mathrm{Ga}, \mathrm{Sr} / \mathrm{Ba}, \mathrm{V} / \mathrm{Zr}$, 与海相泥岩比值十分相近, 而高于陆相泥岩, 也说明 “火山诱积碳酸盐岩”形成于接近海相的咸水或半咸 水环境。

通过对本区沉积环境的分析，该岩石应形成于 与海水局部相通的三角洲分流间湾或坝后泻湖的咸 水或半咸水环境，而且当时曾伴随着强烈的火山喷 发，这恰与对该岩石所做的岩石学、矿物学、岩石化 学及氧、碳同位素的研究完全吻合.

根据 Schmalz 和 Chave (1963) 对百慕大海域 和其它海域所取海水样品的分析, 均证明海水对 $\mathrm{CaCO}_{3}$ 来说是饱和的或过饱和的; 同时根据 W. v. Engelhardt (1977) 的热力学计算, $\mathrm{CaCO}_{3}$ 的溶解度 随水温的升高而降低. 所以，碳酸盐的沉淀只需水 温的稍许提高. 由此可见，在本区强烈火山作用的 影响下,除部分火山灰形成凝灰岩或层凝灰岩外，还 有大量火山灰尘，在炽热状态下沉降于三角洲分流 间湾或坝后泻湖中,由于水温的急剧开高,使 $\mathrm{CaCO}_{3}$, 过饱和,由水中析出的微晶方解石, 围绕火山灰尘形 成大量的碳酸盐“凝块”而发生聚沉，从而形成本区 首次发现的“火山诱积碳酸盐岩”。

“火山诱积碳酸盐岩”的发现, 为碳酸盐的研究 提供了一个新的研究领域, 也为本区晚石炭世火山 活动提供了一个重要的信息.

$$
\begin{gathered}
\text { 贾 炳 文 } \\
\text { (山西矿业学院,太原) }
\end{gathered}
$$

\section{浙江长兴二叠、三叠纪之间的冲击事件}

我们最近对浙江长兴 $\mathrm{P}-\mathrm{T}$ 界线剖面进行了较 详细的研究，发现在界线及其附近有冲击事件发生 的记录.
1. 长兴阶上部灰岩(界线以下 $30 \mathrm{~m}$ 以内)中沉 积构造具有明显的同沉积变形。灰岩分层断面呈明 显的细经化和局部增厚, 分层内部层理随同分层发 
生同步变形,层面出现凸凹起状现象，与成岩期间水 平状含水沉积物发生剧烈振荡后的变形特征相似。

2. 长兴阶下部灰岩(距界线约 $30 \mathrm{~m}$ 以下)分层 间普遍具有明显的挤压滑动迹象. 有滑动擦痕和滑 动镜面，擦痕有大致东西方向延伸的趋势。滑动面 上均有不同程度的石䁪化或糜棱岩化. 局部地区具 有挤压逆冲断层 (D 剖面东侧)。这些可能是成岩后 的下部长兴阶灰岩遭受 P-T 之交冲击事件剧烈推挤 作用的产物。

3. 对 P-T 界线粘土及其上、下地层样品十多 次的 INAA 和 RNAA 分析结果, 表明界线粘土层 及其上覆黑色页岩平均具有高于上、下一个数量级 以上的铱异常。铱丰度一般为 $0 . n \mathrm{ppb}$. 与铱异常 相伴随的还有 $\mathrm{Os} 、 \mathrm{Au} 、 \mathrm{Pt} 、 \mathrm{Ni} 、 \mathrm{Co} 、 \mathrm{Fe} 、 \mathrm{Cu} 、 \mathrm{Cr} 、 \mathrm{Sc}$ 等 元素的同步异常. 上述元素的异常可能与球外成份 的混入有关.

4. 界绕粘土层中发现有较多的硅质、金属质小 球. 有的小球表面还具有放射状裂纹、耳状突起、气 孔等典型宇宙尘的表面特征. $\mathrm{X}$ 射线能谱分析结果 表明,硅质小球主要由 $\mathrm{SiO}_{2}(90 \%$ 以上)组成; 金属

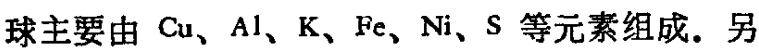
外还含有较多与透长石成份相似的富钾铝硅酸盐小 球.

5. 界线粘土层中 $(z 、 D$ 剖面)有大量的高温型 石英. 它们具有六方双锥、八面体等晶形,石英粒径

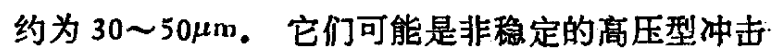
石英后期高温过程中转变的产物。

6. 在界线粘土层中 ( $\mathrm{C}$ 剖面) 还发现有大量细 小的白色和透明的晶体. $\mathrm{x}$ 射线粉晶物相结果表明 这些晶体成份为石高. 说明界线事件期间, 这一地. 区短期内曾达到高温蒸发的环境。

7. 另外,界线粘土层中还见有少量沉积岩和变 质岩岩屑,主要有粉砂岩、泥质岩、变质石英岩等. 粒 径大小不一, 由 $0.05 \sim 2 \mathrm{~mm}$ 不等. 由此可能说明关 于界线粘土层的火山成因解释的可能性是不大的.

目前, 我们正对这些冲击记录进行更详细更深 入的研究. 从这些记录, 我们可以认为: $1 . P-T$ 之 交确实发生了一起规模巨大的冲击事件. 与国内其 它 P-T 界线剖面比较, 浙江长兴地区可能是距冲击 地点相对较近的地区之一;2. 长兴阶灰岩上、下不同: 性质的构造变形，给我们提供了关于灰岩成岩历史 的新启示, 约 $3 \mathrm{~m}$ 厚度的灰岩所代表的沉积时间, 有可能是灰岩从沉积到成岩固化所需要的时间.

周瑶琪 柴之芳 马淑兰毛雪䒨 (中国科学院高能物理研究所, 北京)

何 锦 文 （中国科学院南京古生物研究所） 孙亦因 （中国科学院地质研究所，北京）

\section{合成家蝇性信息素-(Z)-9-廿三碳烯}

家蝇性信息素-(Z)-9-开三碳烯是一种崔性 家 蝇的珄信息索. 由于该化合物对人类的健康卫生防 止疾病等方面意义重大,引起人们对它合成的兴趣. Carlson 等人于 1971 年用三苯基膦十四烷基叶立德 (ylide) 与王醛为原料的 Wittig 反应首先合成出 这
个化合物. 在此之后, 人们不断探索新的合成方法, 到目前为止已经相继报道了许多合成家蝇性信息素 的新方法. 但是报道的这些方法中有一个共同的特 点, 那就是在合成中全都使用金属有机化合物, 有的 作为中间体，有的作为试剂. 这样给实验带来许多.

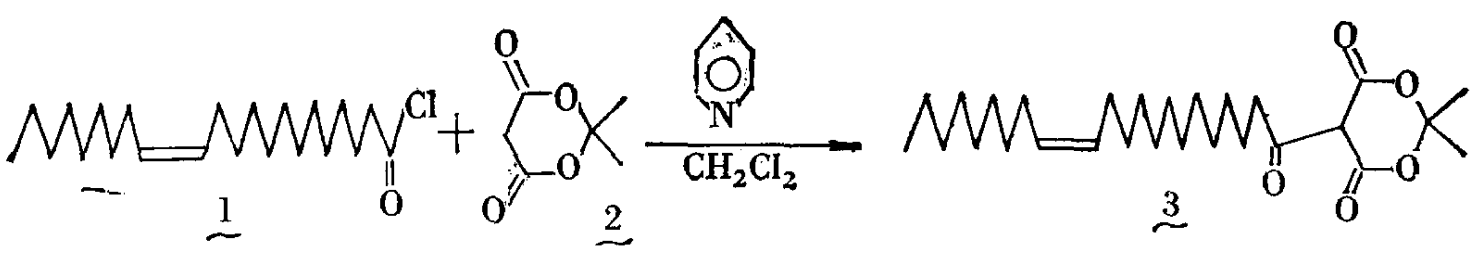

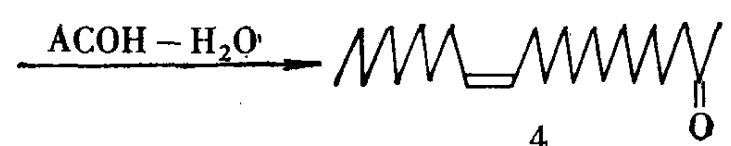

$\underline{4}$

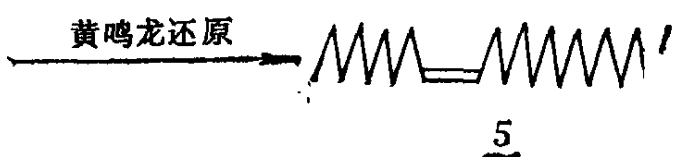

5 